Colombia Médica

\title{
Nasal and vaginal colonization of methicillin-resistant Staphylococcus aureus in pregnant women in Cartagena-Colombia.
}

\section{Colonización nasal y vaginal por Staphylococcus aureus resistente a meticilina en mujeres embarazadas at- endidas en la Clínica Rafael Calvo de Cartagena.}

\author{
Correa, Oscara; Delgado, Kelly ${ }^{\mathrm{b}}$; Rangel, Carlac; Bello, Ana ${ }^{\mathrm{d}}$; Reyes ,Niradiz ${ }^{\mathrm{a}}$
}

${ }^{a}$ Grupo Genética y Biología Molecular, Facultad de Medicina, Universidad de Cartagena, Cartagena

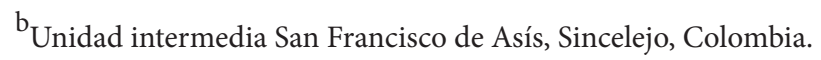

${ }^{\mathrm{c}}$ E.S.E. San Francisco Javier, Margarita, Bolívar, Colombia.

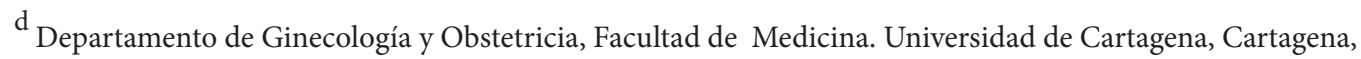

\section{Article history:}

Received Nov 172010

Received in revised form Nov 29

2010

Accepted 3 July 272011

Keywords:

Staphylococcus aureus, methicillin-resistance, maternal colonization, virulence factor, pregnancy.

\section{Palabras clave:}

Staphylococcus aureus, resistencia a meticilina, factores de virulencia, embarazo, colonización.

\begin{abstract}
Introduction. The host niche for Staphylococcus aureus (SA) are the anterior nares; however, vaginal colonization rates between $14 \%-17.1 \%$ in pregnant women have been reported recently, which raises the interest about the potential risk in postpartum women and in neonates from colonized mothers. Objectives. To determine the prevalence of nasal and vaginal colonization of SA and the antibiotic susceptibility of the isolates in pregnant women attending a maternity hospital in Cartagena, Colombia.

Methods. Nasal and vaginal swabs were obtained from participants and subjected to microbiological and molecular assays. A post discharge follow-up was performed for up to four weeks. Results. From one hundred pregnant women enrolled in the study, 34 were colonized with SA; twenty nine only in the nares, three only in the vagina, and two at both sites. Colonization of pregnant women with SA was more common in the nares than in the vagina or at both sites [29/34 $(85.3 \%)$ versus $3 / 34(8.8 \%)$ and 2/34 (5.9\%); $\mathrm{p}<0.05]$. We obtained $36 \mathrm{SA}$ isolates, nine of which $(25 \%)$ were MRSA, one was from the vagina; thus, the overall MRSA colonization rate among pregnant women was 9.0\%. Molecular analysis showed that Panton-Valentine leukocidin (PVL) genes were carried by the vaginal MRSA, seven of the nasal MRSA, and two of the MSSA isolates. Two MRSA isolates carried SCCmec type I and seven carried SCCmec type IV. Conclusions: Nasal colonization rate for SA in the study population was similar to previous reports. However, the frequency of nasal colonization of MRSA was higher while vaginal colonization of SA was lower than previously reported in other studies for similar populations. MRSA isolates obtained showed a community profile.
\end{abstract}

\section{Resumen}

Introducción. Staphylococcus aureus (SA) ha adoptado como nicho habitual las narinas anteriores; sin embargo, recientemente se han reportado tasas de colonización del tracto genital de mujeres embarazadas entre 14\%-17.1\%, lo que acrecienta el interés respecto al riesgo asociado para el neonato y la madre en el posparto.

Objetivo. Determinar la prevalencia de colonización nasal y vaginal por SA y los patrones de susceptibilidad a antibióticos de los aislamientos en una comunidad obstétrica de Cartagena, Colombia.

Métodos. Hisopados nasales y vaginales fueron obtenidos de las participantes y sometidos a ensayos microbiológicos y moleculares. Se realizó seguimiento a la madre y al neonato durante cuatro semanas.

Resultados. De 100 embarazadas participantes 34 estuvieron colonizadas con SA; 29 solamente en fosas nasales, 3 solo vagina, y 2 en ambos sitios anatómicos. La colonización fue más común en fosas nasales que en vagina o en ambos sitios [29/34 (85.3\%) versus $3 / 34(8.8 \%)$ and $2 / 34(5.9 \%)$; $\mathrm{p}<0.05]$. Se obtuvieron 36 aislamientos de SA de los cuales 9 fueron MRSA (25\%), proviniendo uno de vagina; por lo tanto, la tasa de colonización total por MRSA en embarazadas fue 9.0\%. Los genes para la leucocidina de Panton-Valentine (PVL) se detectaron en la cepa MRSA vaginal, siete MRSA nasales, y dos MSSA. Dos aislamientos MRSA portaban el elemento SCCmec tipo I y siete el tipo IV.No se detectó resistencia a otros antibióticos en los aislamientos MRSA, pero tres aislamientos susceptibles a meticilina (MSSA) fueron resistentes a eritromicina.

Conclusiones: Aunque la colonización nasal por SA en la población estudiada estuvo dentro del rango reportado previamente, la colonización nasal por MRSA fue mayor, mientras que la colonización vaginal fue más baja, que las reportadas previamente en otros estudios para poblaciones similares. Los aislamientos MRSA obtenidos presentaron un perfil comunitario.

\section{${ }^{*}$ Corresponding Author.}

E-mail Address :oscarleo27@gmail.com(Correa O) kellyosbourne02@hotmail.com(Delgado K), caparajim18@hotmail.

com(Rangel C), amabet2001@hotmail.com(Bello A) nreyesr@unicartagena.edu.co (Reyes N) 


\section{Introduction}

Staphylococcus aureus (SA) is an important human pathogen responsible for nosocomial and community acquired infections, which also behaves as commensal flora in healthy individuals mainly colonizing the anterior nares ${ }^{1}$. Carriers of SA, in particular Methicillin-resistant Staphylococcus aureus (MRSA), have a higher risk for developing clinical infections, being the infections caused by MRSA strains the most important at the clinical level, since they are more difficult to trea $a^{2}$. In the last decades, MRSA strains, especially those associated to the community (Community associated Methicillin-resistant Staphylococcus aureus, CA-MRSA) have become an important issue in public health, since they are a cause of increased morbidity and mortality ${ }^{3}$. These CA -MRSA strains cause severe skin and soft tissue infections, necrotizing pneumonia and sepsis in otherwise healthy children, teens, and more recently, in neonates. The increasing number of infections in neonates caused by CA-MRSA, emphasizes the need to identify the possible sources of infection, either environmentally or maternally derived ${ }^{4,5}$.

For pregnant women SA also pose a health risk, since it is the main cause of infection of the surgical site, causing between $25 \%$ to 50 $\%$ infections of the post cesarean surgical site, representing a major cause of morbidity and a cause of puerperal mastitis ${ }^{6}$. Early epidemiological studies showed that $5 \%$ of women were colonized with SA in their genital tract and postpartum women had the highest colonization rates; furthermore, vaginal-rectal carriage of SA has been found to be associated with development of postpartum fever ${ }^{7}$. Although risk factors associated to colonization with MRSA strains during pregnancy have not been fully characterized, associations with race, parity, type of birth, and colonization with group $B$ streptococci have been suggested ${ }^{7}$. It is known that incidence of CA-MRSA infections vary among different communities and populations, and apparently, pregnant women are more susceptible and have risk factors that predispose them to develop these infections $6,{ }^{8}$. Despite of this, there is a scarcity of epidemiologic reports about MRSA infections presenting in pregnant and puerperal women ${ }^{6}$.

More recently, several studies, mainly from the United States, have reported vaginal colonization rates for SA in pregnant women from $14 \%$ to $17.1 \%$, and although the risk of vertical transmission has been suggested or even demonstrated $^{9-11}$, the association of such coloni- zation with infant outcome has not been clearly established $^{12}$.

Thus, there is a need to increase the knowledge in this area of research. A literature review of the subject reveals few published studies in this area, which are mainly reviews of clinical cases $^{13}$, making clear that more epidemiology based studies are needed given the increasing importance of CA-MRSA strains in serious neonatal infections ${ }^{14}$ and in women in puerperal stage ${ }^{8}$.

Antibiotic resistance of MRSA strains is due to the acquisition of mecA gene, which codes for PBP-2a, a penicillin binding protein with low binding affinity for beta-lactam antibiotics. MecA gene is located in a mobile genetic element, the chromosomal staphylococcal cassette (SCCmec), of which seven major types have been identified, from I to VII. SCCmec types IV, V and VII are the most frequently found in CA-MRSA isolates, which also frequently carry the genes for Panton-Valentine leukocidin (PVL) ${ }^{15}$.

Up to $96 \%$ of MRSA infections in pregnant women mainly affect the skin and soft tissue, although several cases of pneumonia in the puerperal period have been also attributed to MRSA strains ${ }^{6}$. Since PVL-carrying MRSA strains have been implicated in the development of serious skin and soft tissue infections and in necrotizing pneumonia ${ }^{16}$, in the present study besides determining the SA nasal and vaginal colonization rates and antibiotic profiles of the isolates, we evaluated the presence of PVL genes and SCCmec types of MRSA isolates by multiplex PCR.

\section{Methods}

Design, Study Population, and Inclusion Criteria

The present was a pilot study performed by the Genetics and Molecular Biology Research Group of the University of Cartagena. The study site, Maternity Clinic Rafael Calvo (MCRC), in Cartagena, Colombia, is a university-affiliated maternity clinic attending pregnant women from the urban and rural areas around Cartagena, and whose obstetric service delivers between 8000 and 8500 infants per year. Following a research protocol approved by the Ethics Committee of University of Cartagena and the Institutional Review Board of MCRC, women with at least 35 weeks of gestational age, who attended the outpatient or urgency departments during the months of January through June 2009 were enrolled in the study 
after signing an informed consent. Women with ruptured membranes and those under antibiotic treatment or with clinical evidence suggesting a current staphylococcal infection were excluded from the study. Following approaches previously described by Pinter et $\mathrm{al}^{13}$ and Beigi et al.' nasal and vaginal swabs were obtained from the enrolled pregnant women $(\mathrm{n}=$ 100) with vaginal samples taken from the outer third portion of the vagina. Although the objective of the study was to determine SA nasal and vaginal colonization rates and antibiotic susceptibility, we tried to ascertain any possible associations of colonization with complications related to staphylococcal infection either in the mothers or their newborns implementing a post discharge weekly follow-up by telephone for up to four weeks. Mothers were contacted by telephone at least once a week during her baby's first month of life. They were asked about the general health of her infant as well as her own. Specific questions were asked to determine whether any fevers, rashes, or other skin lesions had occurred in the infant. Additionally, participants were asked to file a questionnaire about social demographic data and medical records.

\section{Laboratory Methods}

Nasal and vaginal specimens were transported to the microbiology laboratory of the School of Medicine at University of Cartagena, and processed within 8 to 18 hours according to protocols described by Bettin et $\mathrm{al}^{17}$. Antibiotic susceptibility of isolates confirmed as SA was performed by the disc diffusion method following recommendations of the Clinical and Laboratory Standards Institute (CLSI). Antibiotics evaluated were: rifampin ( $5 \mathrm{ug})$, clindamycin (2 ug), erythromycin (15 ug), gentamicin (10 ug), vancomycin (30 ug), cefoxitin (30 ug) and oxacillin (1 ug). SA strain ATCC 33591 was used as control. The D-zone test for inducible clindamycin resistance was performed for each isolate according to CLSI method. Isolates were classified as MRSA if they demonstrated resistance to cefoxitin and MSSA if they were susceptible. MRSA were further confirmed by PCR amplification of mecA gene. Both MSSA and MRSA isolates were stored at $-350 \mathrm{C}$ for subsequent molecular studies.

\section{Molecular analysis}

\section{Genomic DNA extraction}

Genomic DNA from each isolate was obtained according to the protocol described by Millar et $\mathrm{al}^{18}$ with some modifications. Briefly, each SA isolate was subcultured in nutrient agar for $24 \mathrm{~h}$ at $37 \mathrm{oC}$. Around 5 colonies were resuspended in $1 \mathrm{ml}$ of Tris $0.5 \mathrm{M}$, centrifuged at $13,000 \mathrm{rpm}$ $\mathrm{x} 5 \mathrm{~min}$. Supernatant was discarded and the pellet resuspended in $500 \mathrm{ul}$ buffer TE $(10 \mathrm{mM}$ Tris; $1 \mathrm{mM}$ EDTA, $\mathrm{pH}: 8.0$ ) and boiled at $100^{\circ} \mathrm{C}$ for $30 \mathrm{~min}$, and then incubated at $-35^{\circ} \mathrm{C}$ for 20 minutes, thawed at $65^{\circ} \mathrm{C}$ and finally centrifuged at $13.000 \mathrm{rpm}$ for 15 minutes. Supernatant containing bacterial DNA was collected in a clean tube and stored at $-20^{\circ} \mathrm{C}$ for subsequent PCR assays.

\section{Multiplex PCR assays}

Multiplex polymerase chain reaction assays for assessments of presence of the lukF-PV (encoding part of the PVL toxin), mecA, and nuc genes were performed for all SA isolates using previous described primers ${ }^{19-21}$. SA strains ATCC 33591 (mecA +; nuc +; PVL -) and ATCC 25923 (mecA - ; nuc +; PVL +) were used as amplification controls and pure water as negative control. All SA isolates were subjected to multiplex PCR using a set of three primer pairs previously reported: MecA1F - MecA2R that amplifies a $147 \mathrm{bp}$ fragment of mecA gene; Nuc1F - Nuc2R that amplifies a 300 bp fragment of nuc gene specific for SA, and LukPVIF - LukPV2R that amplifies a 437 bp fragment of PVL gene. Additionally, all confirmed MRSA isolates were subjected to SCCmec typing using a multiplex PCR assay. according to the protocol described by Zhang et al. ${ }^{19}$ using SA strains NCTC10442 for SCCmec type I, N315 for SCCmec type II, and JCSC4744 for SCCmec type IV. PCR products were visualized in a $2 \%$ agarose gel stained with ethidium bromide under UV transillumination.

\section{Statistical Analysis}

Statistical analysis was performed with SPSS version 13.0 for Windows. Based on microbiological results, the study population was classified as carrier and non-carrier, and subclassified according to the colonization site (vagina/ nares/both) and the frequency of colonization was determined for each of the two anatomical sites studied. Univariate analysis was applied to determine association of colonization to potential risk factors using the Fisher exact test using a $p$ value $\leq 0.05$ for statistical significance.

\section{Results And Discussion}

Table 1 shows demographic data from our study population and Table 2 shows the general results of SA isolates from this study. One hundred pregnant women were enrolled in this pilot study during a 6-month period and 34 of 


\begin{tabular}{lll}
\hline Variables & & Value \\
\hline Age (years) & Mean & 23,3 \\
& SD & \pm 5 \\
Gestational age (weeks) & Mean & 37,7 \\
Geographical origin & SD & \pm 2 \\
& Urban & 74 \\
Marital status & Rural & 26 \\
& Single & 13 \\
Scholarity & Married & 10 \\
& Unmarried partner & 77 \\
& Primary & 42 \\
& Secondary & 22 \\
Parity & Technical & 21 \\
& Universitary & 4 \\
& None & 11 \\
& Nullipara & 35 \\
& Multipara & 65 \\
\hline
\end{tabular}

Table 1. General demographic characteristics of study population $(\mathrm{n}=100), S D$ : standard deviation

them were colonized with SA. Twenty nine of them were colonized only in the nares, three were colonized only in the vagina, and two harbored S. aureus at both sites. Colonization of pregnant women with SA was more common in the nares than in the vagina or at both sites $[29 / 34(85.3 \%)$ versus $3 / 34(8.8 \%)$ and $2 / 34$ $(5.9 \%) ; \mathrm{p}<0.05]$. From the total of participants, we obtained 36 SA isolates, nine of which $(25 \%)$ were MRSA, one was from the vagina; thus, the overall MRSA colonization rate among pregnant women was $9.0 \%$.

The nasal colonization rate for SA found in our pilot study (29\%) was similar to rates previously reported for general population ${ }^{2,22}$. However, the nasal colonization by MRSA ( $8 \%$ of the overall population of this study, $27.6 \%$ of the nasal SA isolates) was higher than the frequencies previously described both at international

\begin{tabular}{|c|c|c|c|}
\hline \multirow[t]{2}{*}{ Site } & \multirow[t]{2}{*}{ SA neg } & \multicolumn{2}{|l|}{$\begin{array}{l}\text { SA pos } \\
(\mathrm{n}=36)\end{array}$} \\
\hline & & MSSA & MRSA \\
\hline Nasal & 69 & 23 & 8 \\
\hline Vaginal & 95 & 2 & 1 \\
\hline Both & 98 & 2 & 0 \\
\hline
\end{tabular}


and national level ${ }^{22}$. Albeit, at local level there is a report of similar nasal colonization rate for MRSA in scholar children ${ }^{23}$ in other local report MRSA nasal isolates were no detected among elderly people residing in a nursing-ho$\mathrm{me}^{17}$. To our knowledge, the colonization for SA in pregnant women have not been evaluated previously in Colombia.

We found in this pilot study a 3\% vaginal and $2 \%$ nasal and vaginal colonization rates for SA, which are comparable to rates reported in similar studies in geographically different populations $s^{9,12}$, and a $29 \%$ nasal colonization rate, which is in the range described in other similar studies, $^{9}$. For MRSA, nasal colonization rate in this group of pregnant women were much higher $(8 \%)$ than the rates reported for the general population ${ }^{15,24}$ and for pregnant women in different geographical areas ${ }^{13}$. For example, a pilot study carried out in Cleveland-Ohio reported that $22 \%$ of the study population were nasal carriers of $\mathrm{SA}^{9}$. The authors of that study referenced a former report published in 1978 where the nasal colonization of SA in pregnant women was $4.0 \%$. In a study similar to ours, Pinter et al. reported that from 304 pregnant women, $34(11.2 \%)$ of them were colonized in the nares, 7 of whom (2.3\%) were colonized with MRSA ${ }^{13}$.

Most recent data on SA colonization in obstetrics (both MSSA and MRSA) are derived mainly from the USA ${ }^{5,9-11,13}$ or Europe ${ }^{12}$, and until now they provide little evidence that either universal or targeted screening is beneficial for mothers or babies ${ }^{5,11}, 13,24,25$. Higher colonization rates with SA are observed when the samples are from rectal-vaginal samples ${ }^{10,11}$ compared to vaginal ${ }^{12,13}$, which may reflect the fact that SA colonizes frequently the gastrointestinal tract. In the study published by Andrews et al. ${ }^{11}$, genital tract colonization by MRSA among pregnant women was evaluated and correlated with infant outcome. From 5732 pregnant women participating in the study, 833 were colonized by SA (14.5\%), 202 of whom were MRSA positive (3.5\% overall MRSA colonization). The authors reported that no cases of early-onset invasive neonatal infection by MRSA occurred among infants in their study.

In the pilot study presented here, from 100 pregnant women screened, only 5 vaginal isotates were obtained, one of which was MRSA. Social demographic characteristics of our study population are summarized in Table 1. Statistical analysis of this data did not show significant associations with carrier state. This may reflect the fact that our sample population was small, although similar studies with larger populations have also failed to identify risk factors for SA colonization in pregnant women and the implications for maternal and neonatal outcomes $^{5,11,12}$. In our study, follow up could only be completed for 52 mother-infant pairs, and we did not observe SA related complications neither in mothers nor in newborns; thus, we could not identify factors associated to a higher risk of colonization or development of complications either in mothers or infants. To date, rectal vaginal colonization of SA has been associated to race, parity, route of birth, and colonization by Streptococcus agalactiae ${ }^{7}$. In fact,

\begin{tabular}{lll}
\hline Characteristics & & Number of isolates \\
\hline \multirow{2}{*}{ Origin } & Nasal & 8 \\
& Vaginal & 1 \\
\multirow{2}{*}{ PVL* carrying } & Positive & 7 \\
& Negative & 2 \\
\multirow{2}{*}{ SCCmec types } & Type I & 2 \\
& Type IV & 7 \\
\hline
\end{tabular}

Table 3. Characteristics of Methicillin-Resistant Staphylococcus aureus isolates ( $\mathrm{n}=$ 9) *PVL: Panton-Valentine Leukocidin *SCCmec: Staphylococcal Chromosomal Cassette mec. 


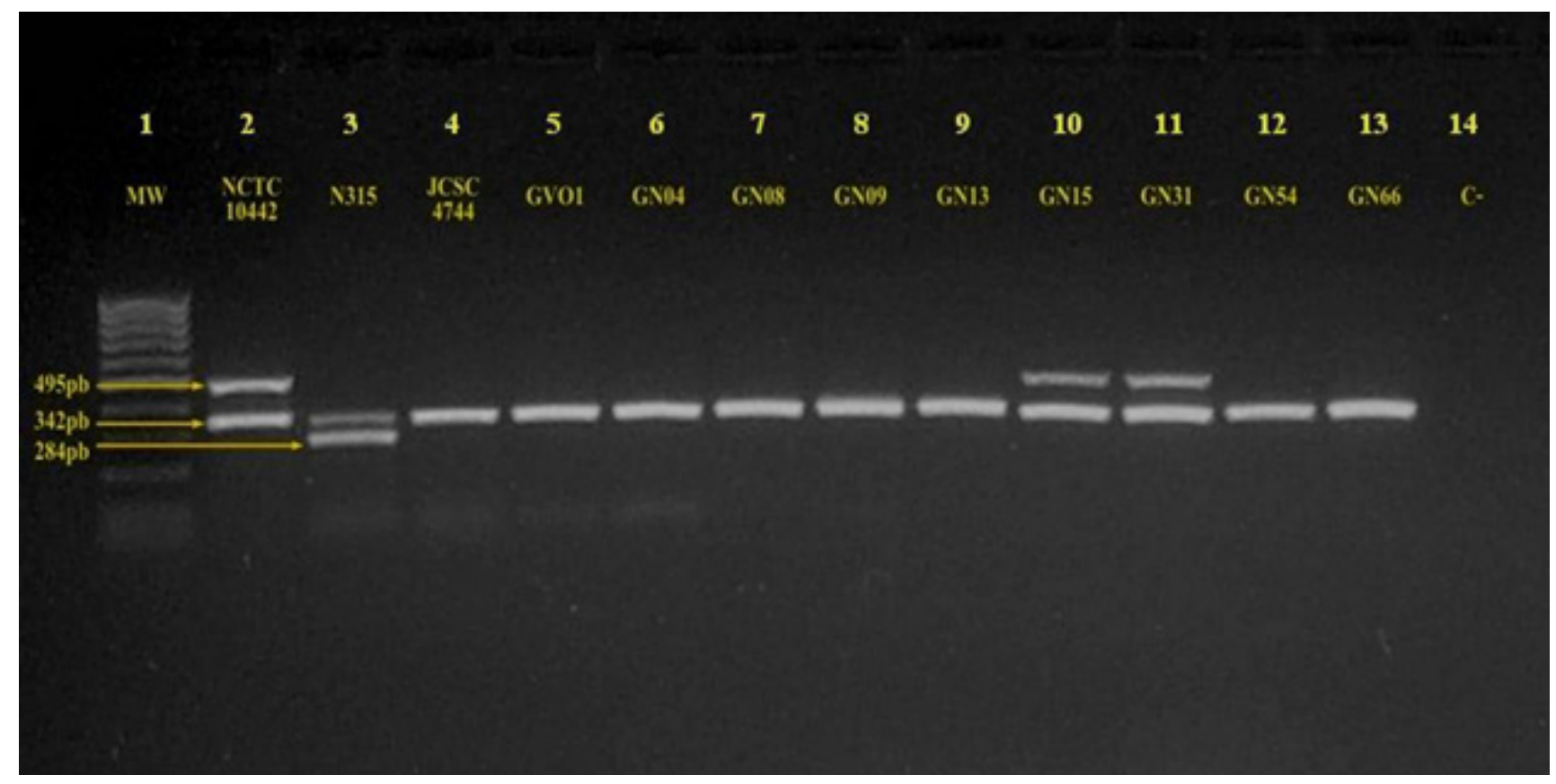

Figure 1. Multiplex PCR for SCCmec typing, Results for SCCmec typing by multiplex PCR. Lane 1: MW (DNA molecular weight marker). Lanes 2, 3, and 4 show results for SA strains NCTC10442 (SCCmec type I), N315 (SCCmec type II), and JCSC4744 (SCCmec IV). Lanes 5 to 13 show SCCmec typing results for MRSA isolates from the study. Two MRSA isolates were SCCmec type I (Lanes 10 and 11). Seven MRSA isolates were SCCmec type IV (Lanes 5 to 9 and Lanes 12 and 13). Lane 14 shows the results for a negative control of the PCR reactions.

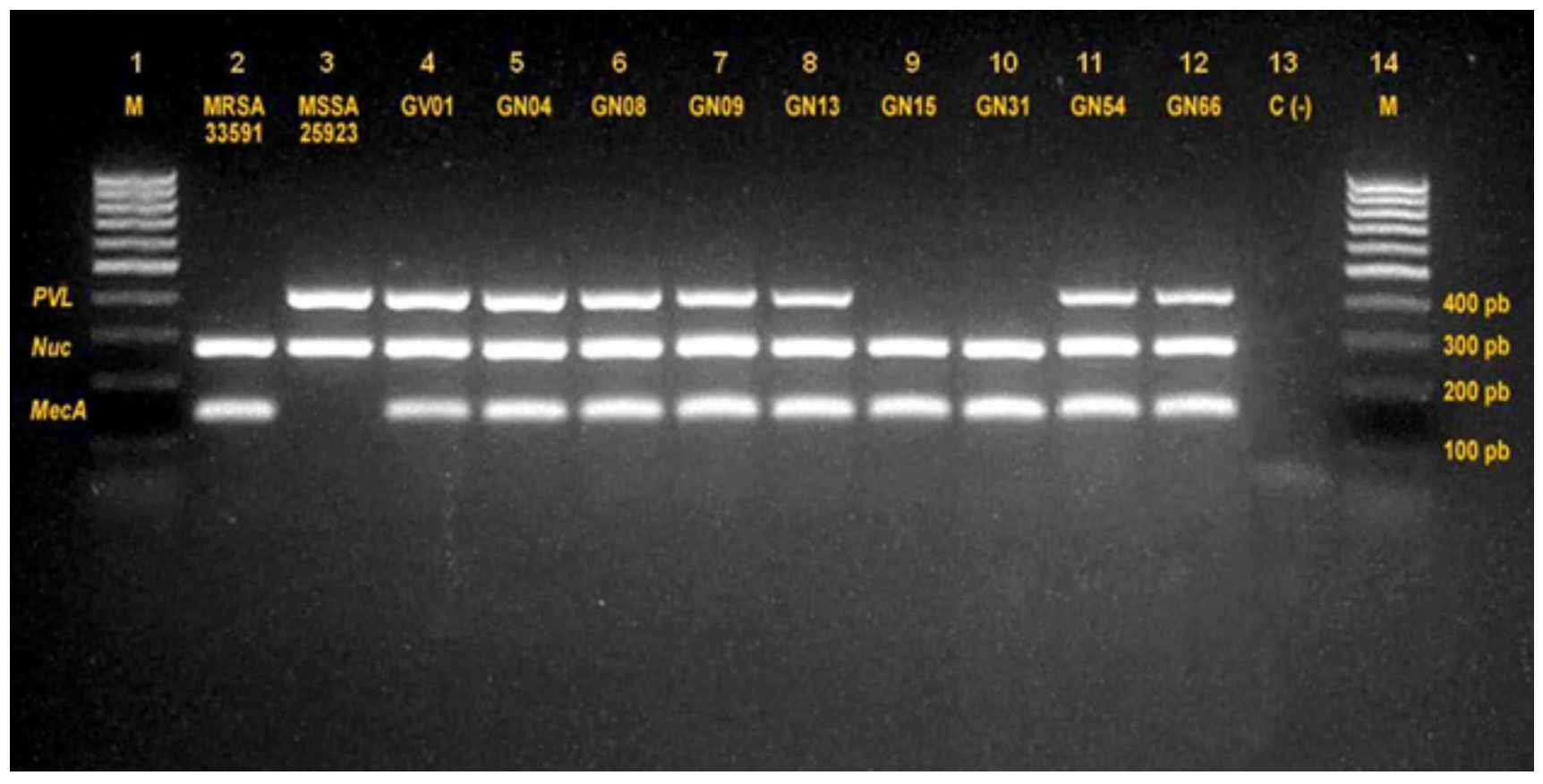

Figure 2. Multiplex PCR for detection of nuc, mecA, and PVL genes, Multiplex PCR was carried out to detect the presence of nuc, mecA and PVL genes in isolates from pregnant women to confirm Staphylococcus aureus species (nuc gene), methicillin resistance (mecA gene) and presence of PVL genes. Lanes 1 and 14: M (DNA molecular weight markers). Lanes 2 and 3 : ATCC 33591 reference strain (nuc+, mecA+, PVL-) and ATCC 25923 reference strain (nuc+, mecA-, PVL+) respectively. Lanes 4 to 12: representative isolates from the study. Lane 13: negative control of the PCR reactions. 
Chen et al. reported that patients that were colonized by S. agalactiae were also more likely to be colonized with SA, but those colonized by MRSA were not colonized with S. agalactiae ${ }^{7}$.

It is of interest to compare our current results for maternal colonization with SA and MRSA with those of Pinter et al. ${ }^{13}$, who reported a maternal colonization rate of $14.1 \%$ for SA and of $3 \%$ for MRSA, much lower to the reported in the current study. It should be noted, for comparison, that in the study by Pinter et al. all participants delivering their babies by the vaginal route were screened on the day of delivery at both the nares and the vagina in contrast with the current study in which pregnant women were screened at both the nares and vagina between 35 and 42 weeks of gestational age, 17\% of whom were in labor at the time of sampling. Whether differences in the colonization rates are related to differences in geographical areas or in the methodology used is uncertain.

Although asymptomatic nasal, vaginal, and rectal colonization with MRSA have been reported to occur in some pregnancy-related clinical cases in which SA colonization has been identified as risk factors for serious systemic infection after delivery ${ }^{8}$, epidemiological studies show that universal screening and decolonization efforts in pregnant women are currently non cost-effective ${ }^{2,25}$. Similarly, there is no current evidence that vertical transmission of SA constitute a significant risk for neonatal complications, although vertical transmission of SA have been documented in some studies ${ }^{4}$ 13 .

In our pilot study, antibiotic susceptibility of the SA isolates found that all MRSA isolates had the resistance profile associated to the community, with exclusive resistance to methicillin. Also, three MSSA isolates had erythromycin resistance; one of them had the erythromycin inducible clindamycin resistance phenotype, detected by the D-test. We did not find resistance to other antibiotics neither in MRSA nor MSSA isolates.

Table 3 summarizes the characteristics of MRSA isolates. SCCmec typing by multiplex PCR assay (Figure 1), showed that among the MRSA isolates from this study, two had SCCmec type I and seven had SCCmec type IV, data consistent with community-associated MRSA since it has been previously reported that MRSA isolates commonly found in community settings frequently bear SCCmec type IV (and V) ${ }^{15}$.
Although controversial, Panton-Valentine leukocidin has been widely regarded as a major virulence determinant associated to epidemic clones of CA-MRSA in the world16. In the current study we determined the presence of PVL genes among SA isolates, both MSSA and MRSA. Among MRSA isolates, six nasal isolates and the vaginal isolate were PVL positive (Figure 2). In contrast, among the MSSA isolates, only two were PVL positive; thus, PVL genes were more frequently found in MRSA isolates compared to MSSA [7/9(77.7\%) versus $2 / 27(7.4 \%) ; \mathrm{p}<0.01]$.

\section{Conclusions}

Although the current was a small pilot study and it may not be generalized to the entire pregnant population, the colonization rates found for MRSA were high, as were high the frequency of PVL positive MRSA isolates, emphasizing the need for further epidemiologic studies addressed to evaluate the impact of this colonization in puerperal and neonatal morbidity in our geographical region and to identify subpopulations of pregnant women that may benefit from SA screening, since morbidity and associated costs for MRSA infections in this population are increasingly reported ${ }^{6,8}$.

We could not find statistical significance among socio demographic factors, colonization status and development of complications, which could be attributed to the low number of participants able to complete the follow up. Thus, additional studies with more epidemiologic power are needed to ascertain the role of $\mathrm{SA}$ colonization in pregnant women from our region.

Antibiotic susceptibility profiles, SCCmec typing, and presence of PVL genes of MRSA isolates points out to their community origin.

\section{Conflict Of Interest}

The authors declare that they do not have any conflict of interest related to this study.

\section{Acknowledgements}

This work was supported by the Universidad de Cartagena to Niradiz Reyes, PhD, Principal Investigator. We are thankful to Javier Escobar from the Laboratory of Bacterial Molecular Genetics at Universidad El Bosque for technical assistance in the multiplex PCR assays; to Enrique Jiménez for collaboration in sample taking, to Alfonso Bettín and Juan Rebollo for assistance in laboratory protocols. 


\section{References}

1. Peacock SJ, de Silva I, Lowy FD. What determines nasal carriage of Staphylococcus aureus? Trends Microbiol 2001;9:605-10.

2. Safdar N, Bradley EA. The risk of infection after nasal colonization with Staphylococcus aureus. Am J Med 2008;121:310-5.

3. Zetola N, Francis JS, Nuermberger EL, Bishai WR. Communityacquired methicillin-resistant Staphylococcus aureus: an emerging threat. . Lancet Infect Dis 2005;5:275-86.

4. Huang YC, Chao AS, Chang SD, et al. Association of Staphylococcus aureus colonization in parturient mothers and their babies. Pediatr Infect Dis J 2009;28:742-4.

5. Reusch M, Ghosh P, Ham C, Klotchko A, Singapuri S, Everett G. Prevalence of MRSA colonization in peripartum mothers and their newborn infants. Scand J Infect Dis 2008;40:667-71.

6. Laibl VR, Sheffield JS, Roberts S, McIntire DD, Trevino S, Wendel GD, Jr. Clinical presentation of community-acquired methicillin-resistant Staphylococcus aureus in pregnancy. Obstet Gynecol 2005;106:461-5.

7. Chen KT, Campbell H, Borrell LN, Huard RC, Saiman L, Della-Latta P. Predictors and outcomes for pregnant women with vaginal -rectal carriage of community-associated methicillin-resistant Staphylococcus aureus. Am J Perinatol 2007;24:235-40.

8. Stumpf PG, Flores M, Murillo J. Serious postpartum infection due to MRSA in an asymptomatic carrier: case report and review. Am J Perinatol 2008;25:413-5.

9. Beigi R, Hanrahan J. Staphylococcus aureus and MRSA colonization rates among gravidas admitted to labor and delivery: a pilot study. Infect Dis Obstet Gynecol 2007;2007:70876.

10. Chen KT, Huard RC, Della-Latta P, Saiman L. Prevalence of methicillin-sensitive and methicillin-resistant Staphylococcus aureus in pregnant women. Obstet Gynecol 2006;108:482-7.

11. Andrews WW, Schelonka R, Waites K, Stamm A, Cliver SP, Moser S. Genital tract methicillin-resistant Staphylococcus aureus: risk of vertical transmission in pregnant women. Obstet Gynecol 2008;111:113-8.

12. Bourgeois-Nicolaos N, Lucet JC, Daubie $\mathrm{C}$, et al. Maternal vaginal colonisation by
Staphylococcus aureus and newborn acquisition at delivery. Paediatr Perinat Epidemiol 2010;24:488-91.

13. Pinter DM, Mandel J, Hulten KG, Minkoff $\mathrm{H}$, Tosi MF. Maternal-infant perinatal transmission of methicillin-resistant and methicillin-sensitive Staphylococcus aureus. Am J Perinatol 2009;26:145-51.

14. Dehority W, Wang E, Vernon PS, Lee C, Perdreau-Remington F, Bradley J. Community-associated methicillin-resistant Staphylococcus aureus necrotizing fasciitis in a neonate. Pediatr Infect Dis J 2006;25:1080-1.

15. Deurenberg RH, Stobberingh EE. The molecular evolution of hospital- and community -associated methicillin-resistant Staphylococcus aureus. Curr Mol Med 2009;9:100-15.

16. Diep BA, Otto M. The role of virulence determinants in community-associated MRSA pathogenesis. Trends Microbiol 2008;16:361-9.

17. Bettin A, Suarez P, Bedoya A, Reyes N. [Staphylococcus aureus in residents from a nursing-home in Cartagena]. Rev Salud Publica (Bogota) 2008;10:650-7.

18. Millar BC, Jiru X, Moore JE, Earle JA. A simple and sensitive method to extract bacterial, yeast and fungal DNA from blood culture material. J Microbiol Methods 2000;42:139-47.

19. Zhang K, McClure JA, Elsayed S, Louie T, Conly JM. Novel multiplex PCR assay for characterization and concomitant subtyping of staphylococcal cassette chromosome mec types I to $\mathrm{V}$ in methicillin-resistant Staphylococcus aureus. J Clin Microbiol 2005;43:5026-33.

20. Brakstad OG, Aasbakk K, Maeland JA. Detection of Staphylococcus aureus by polymerase chain reaction amplification of the nuc gene. J Clin Microbiol 1992;30:1654-60.

21. Lina G, Piemont Y, Godail-Gamot F, et al. Involvement of Panton-Valentine leukocidin -producing Staphylococcus aureus in primary skin infections and pneumonia. Clin Infect Dis 1999;29:1128-32.

22. Olarte NM, Valderrama IA, Reyes KR, et al. [Methicillin-resistant Staphylococcus aureus colonization in a Colombian hospital intensive care unit: phenotypic and molecular characterization.]. Biomedica 2010;30:353-61.

23. Castro-Orozco R, Villafane-Ferrer LM, Alvarez-Rivera E, De Arco MM, Rambaut-Dona- 
do CL, Vitola-Heins GV. [Methicillin-resistant Staphylococcus aureus in children attending school in Cartagena, Colombia]. Rev Salud Publica (Bogota) 2010;12:454-63.

24. Gray J, Patwardhan SC, Martin W. Meticillin -resistant Staphylococcus aureus screening in obstetrics: a review. J Hosp Infect 2010;75:8992.

25. Beigi RH, Bunge K, Song Y, Lee BY. Epidemiologic and economic effect of methicillin -resistant Staphylococcus aureus in obstetrics. Obstet Gynecol 2009;113:983-91. 